doso en la 1

ar ejemplos a

is funcionalidac uso, dependiende encarnan los conceptos detr por e $\Lambda$ influ
$\mathrm{Pe}$ infin:

Las formas $d r$ oceso de sig ialidad .

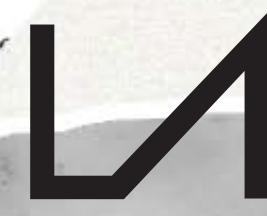

R E V I S A
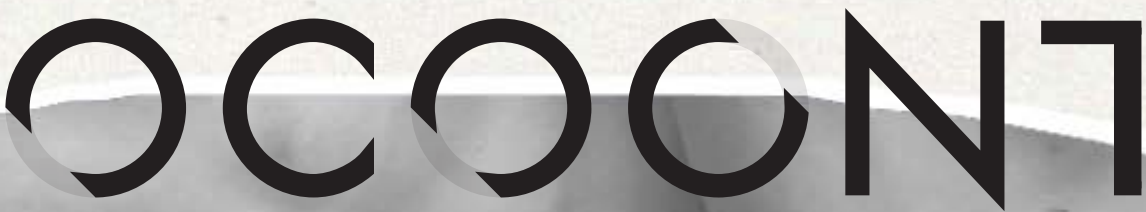

D $E$

No $6 \cdot 2019 \cdot$ ISSN 2386-8449

"El producto del diseñador es un proyecto, el estado previo de un objeto", Entrevista con Norberto Chaves, por Fernando Infante

El papel de la investigación y la teoría en diseño. Una conversación abierta, por Fernando Infante y María Jesús Godoy

UT PICTURA POESIS

Abandonar la escritura. Poesía experimental y manifiesta, Ignacio Gómez de Liaño

PANORAMA: FILOSOFÍA DEL DISEÑO Sección coordinada por Fernando Infante y María Jesús Godoy

Pensar el diseño, Fernando Infante y María Jesús Godoy (Coordinadores)

TEXTOS INVITADOS

Estatus y estado del điseño más allá del objeto, Pedro Medina Reinón

Mar de Nubes, Cuerpo de Cristal, Dionisio González

ARTÍCULOS

Understanding Design Aesthetics beyond Functional Beauty accounts, Lucía Jiménez Sánchez

Estética y diseño industrial: debates y controversias, Joan M. Marín

Del ornamento al delito. El diseño y la sociedad en Charles Baudelaire y Adolf Loos, Jorge López Lloret

When is Architecture not Design? Saul Fisher

Diseño y habitabilidad: una aproximación basada en los lenguajes de patrones, Antonio Hidalgo Pérez

Marcel Breuer: un diseñador global. Experiencias en el ámbito de la vivienda prefabricada, Salvador J. Sanchis, Ignacio Peris y Pedro Ponce Diseño y artes escénicas: el papel de Oskar Schlemmer en Das Triadische Ballett y la actualidad de la Bauhaus, Milagros García Vázquez Lo performativo en prácticas de arte y diseño actuales vinculadas a procesos de innovación social. El caso de La Venezia che non si vede y de La borda, Tània Costa Gomez

Articulaciones de la estética y el diseño. El caso de la evaluación a partir de la investigación dirigida en la carrera de diseño escénico de la Universidad de las Artes de Cuba, Mara Rodríguez Venegas y Xiomara Romero Rojas

SUPLEMENTO

El diseño, la ciudad y un lápiz de labios, Mercedes Espiau, Mar García Ranedo y Alejandro Rojas mas. 


\section{UつCつCNTE}

No $6 \cdot 2019 \cdot \operatorname{ISSN} 2386-8449 \cdot$ DOI 10.7203/LAOCOONTE.5.15381

https://ojs.uv.es/index.php/LAOCOONTE/index

COORDINACIÓN EDITORIAL

Anacleto Ferrer (Universitat de València)

Francesc Jesús Hernàndez i Dobon (Universitat de València)

Fernando Infante del Rosal (Universidad de Sevilla)

SECRETARÍA DE REDACCIÓN

Lurdes Valls Crespo (Universitat de València)

Vanessa Vidal Mayor (Universitat de València)

COMITÉ DE REDACCIÓN

Tamara Djermanović (Universitat Pompeu Fabra), Rosa Fernández Gómez (Universidad de Málaga), Anacleto Ferrer (Universitat de València), Ilia Galán (Universidad Carlos III), Ana María García Varas (Universidad de Zaragoza), María Jesús Godoy (Universidad de Sevilla), Fernando Infante del Rosal (Universidad de Sevilla), Miguel Ángel Rivero (Universidad de Sevilla), Miguel Salmerón (Universidad Autónoma de Madrid), Gerard Vilar (Universitat Autònoma de Barcelona).

COMITÉ CIENTÍFICO INTERNACIONAL

Rafael Argullol* (Universitat Pompeu Fabra), Luis Camnitzer (State University of New York), José Bragança de Miranda (Universidade Nova de Lisboa), Bruno Corà (Università di Cassino), Román de la Calle* (Universitat de València), Eberhard Geisler (Johannes Gutenberg-Universität Mainz), José Jiménez* (Universidad Autónoma de Madrid), Jacinto Lageira (Université Paris 1 Panthéon-Sorbonne), Bernard Marcadé (École Nationale Supérieure d'Arts de Paris-Cergy), Elena Oliveras (Universidad de Buenos Aires y Universidad del Salvador), Pablo Oyarzun (Universidad de Chile), Francisca Pérez Carreño* (Universidad de Murcia), Bernardo Pinto de Almeida (Faculdade de Belas Artes da Universidade do Porto), Luigi Russo (Università di Palermo), Georges Sebbag (Doctor en Filosofía e historiador del surrealismo), Zoltán Somhegyi (University of Sharjah, United Arab Emirates), Robert Wilkinson (Open University-Scotland), Martín Zubiria (Universidad Nacional de Cuyo). *Miembros de la Sociedad Española de Estética y Teoría de las Artes, SEyTA

\begin{tabular}{lll}
\hline DIRECCIÓN DE ARTE & REVISIÓN DE TEXTOS & TRANSCRIPCIÓN DE TEXTOS \\
El golpe. Cultura del entorno & Antonio Cuesta & Álvaro G. Serna
\end{tabular}

(cc) BY Excepto que se establezca de otra forma, el contenido de esta revista cuenta con una licencia Creative Commons Atribución 3.0 España, que puede consultarse en http://creativecommons.org/licenses/by/3.0/es/deed.es

EDITA

\section{SEyTA.}

CON LA COLABORACIÓN DE

\begin{tabular}{|c|c|c|c|}
\hline $\begin{array}{l}\text { VNIVERSITAT } \\
\text { B VALENCIA } \\
\text { Institut te Creativitat } \\
\text { | |nnovacions Educatives }\end{array}$ & $\begin{array}{l}\text { VNIVERSITAT } \\
\text { IE ÖVALENCIA Departament de Filosofia }\end{array}$ & 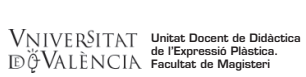 & \\
\hline $\begin{array}{l}\text { DEPARTAMENTO DE ESTÉTICA } \\
\text { E HISTORIA DE LA FLLOSOFIA }\end{array}$ & $\frac{\text { UAW }}{\frac{\text { UNIVRSSIDAD AUTONOMA }}{\text { DE MADRID }}}$ & $\begin{array}{l}\text { Universitat Autònoma } \\
\text { de Barcelona }\end{array}$ & $\begin{array}{l}\text { VNiVERSiDAD } \\
\text { Departamento de Filosofia, Lógica y Estética }\end{array}$ \\
\hline
\end{tabular}

LAOCOONTE aparece en los catálogos: 


\section{LつCつCN7E}

"Cuanto más penetramos en una obra de arte más pensamientos suscita ella en nosotros, y cuantos más pensamientos suscite tanto más debemos creer que estamos penetrando en ella".

G. E. Lessing, Laocoonte o los límites entre la pintura y la poesía, 1766.

Vo hay cól.

létodo, de pen.

:ión en general. Ith

zar la forma para el $\mathrm{n}$.

eptual por las orígenes

la, el objeto, la exposición

storia, porque existe en el $\mathrm{m}$

das sus raíces. Desde alli cc _. panoram

n conceptual y donde el émencia del con 'iseñado, como es el a al objeto y el di $\begin{array}{ll}\text { igen } \mathrm{de}^{\text {to }} \text { la inmer } & \text { tolvidada, o comc } \\ \text { trozo de madera ar }\end{array}$ a manera dorm comunicar ene nundo. Seguin? sngo en manos te el método $C$ les. A partir c teria prima $\mathrm{p}_{\mathbf{c}}$

'xto se puede:

¿ño, en proyea

amientos de $\mathrm{u}$

a conscie-

.)

en la publicación jue "plos de la impor te las nalidades porqu ura un ${ }^{2}$ diendo de qui zenerar $\mathrm{u}$ ción de nr? lne

in-

n-

is.

le http:,

le crear visualidades. A partir de.

ellas la propia materia prima para un en que desde un texto se puede generar $u_{11}$ i

Pensar en diseño, en proyección de nue

posibles comportamientos de una colecti

presente como una consciencia del hecho que estamos elaborando, significac

nuestro entorno (..)

Cardoso, R. C. Rafael. (2014). Design para um mundo complexo. Sãc asil: Cosac Naify. 


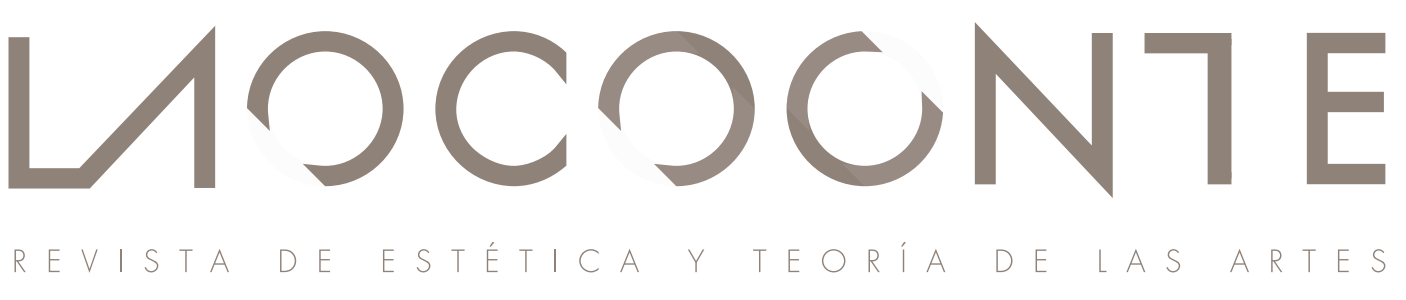

$\mathrm{N}^{\circ} 6 \cdot 2019$

PRESENTACIÓN

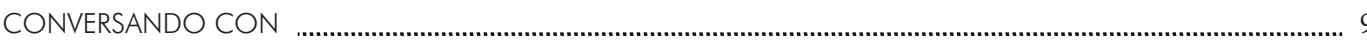

"El producto del diseñador es un proyecto, el estado previo de un objeto", Entrevista con Norberto Chaves,

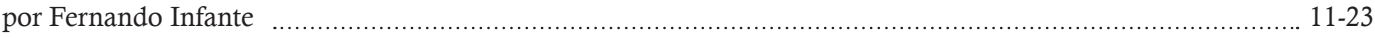

El papel de la investigación y la teoría en diseño. Una conversación abierta, por Fernando Infante

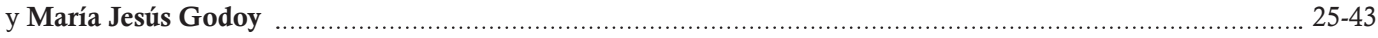

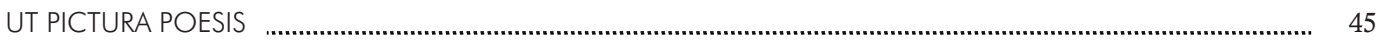

Abandonar la escritura. Poesía experimental y manifiesta, Ignacio Gómez de Liaño ................................................ 47-95

Imágenes de Laocoonte n. 6, de Isadora Gonzaga ................................................................................................... 96-97

PANORAMA

FILOSOFÍA DEL DISEÑO

Pensar el diseño, Fernando Infante y María Jesús Godoy (Coordinadores) .............................................. 101-105

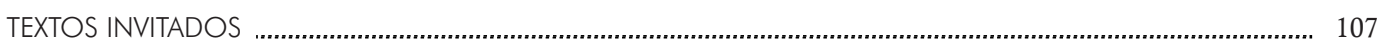

Estatus y estado del diseño más allá del objeto, Pedro Medina Reinón . ................................................... 109-125

Mar de Nubes. Cuerpo de Cristal, Dionisio González .............................................................................. 127-133

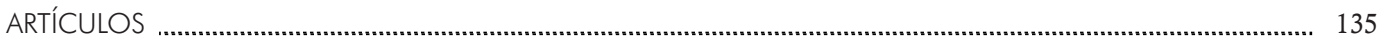

Understanding Design Aesthetics beyond Functional Beauty accounts, Lucía Jiménez Sánchez ................. 137-149

Estética y diseño industrial: debates y controversias, Joan M. Marín _...................................................... 150-164

Del ornamento al delito. El diseño y la sociedad en Charles Baudelaire y Adolf Loos, Jorge López Lloret ... $165-182$

When is Architecture not Design? Saul Fisher ……............................................................................. 183-198

Diseño y habitabilidad: una aproximación basada en los lenguajes de patrones, Antonio Hidalgo Pérez ...... 199-215

Marcel Breuer: un diseñador global. Experiencias en el ámbito de la vivienda prefabricada,

Salvador José Sanchis, Ignacio Peris y Pedro Ponce

Diseño y artes escénicas: el papel de Oskar Schlemmer en Das Triadische Ballett y la actualidad de la Bauhaus, Milagros García Vázquez

Lo performativo en prácticas de arte y diseño actuales vinculadas a procesos de innovación social.

El caso de La Venezia che non si vede y de La borda, Tània Costa Gomez

Articulaciones de la estética y el diseño. El caso de la evaluación a partir de la investigación dirigida en la carrera de diseño escénico de la Universidad de las Artes de Cuba, Mara Rodríguez Venegas

y Xiomara Romero Rojas

SUPLEMENTO 
Walter Gropius. La vida del fundador de la Bauhaus, Jorge Martínez Alcaide

¿Qué significa pensar la política desde la estética? Àger Pérez Casanovas

Ideologías estéticas en los orígenes de la pintura moderna, José Luis Plaza Chillón 300-303

Sobre a estética, Luis Carlos Pereira

Músicas populares. Sociedad y territorio: Sinergias entre investigación y docencia, Mar Aleixandre Badenes.

307-309

La necesidad de la mirada antropológica sobre la literatura, Pablo de Benito David

A propósito de Chandler, o la novela policíaca como tratado filosófico, Juan Evaristo Valls Boix

Videre aude!, Anacleto Ferrer

La inaplazable memoria del dolor y el sufrimiento, Antonio Notario Ruiz

La alargada sombra de la pintura, Raquel Baixauli

Sondear la maravilla, Juan Evaristo Valls Boix

... Y lo sabes, Marc Hernández Montoro

Arqueologías de la modernidad en las artes. Ensayo estético, Carlota Fernández-Jáuregui Rojas

Estética de la Instalación, Luis Cemillán Casis

La Herencia de otra época, María Jesús Godoy Domínguez

Del Theatrum Mundi al Gran Vidrio, Miguel Salmerón Infante

Imágenes de Isadora Gonzaga.

Fotografía de portada de Tamara Djermanovic intervenida por Isadora Gonzaga.

Los coordinadores de la sección Panorama: Filosofia del diseño agradecen

a Antonio Molina Flores su colaboración. 


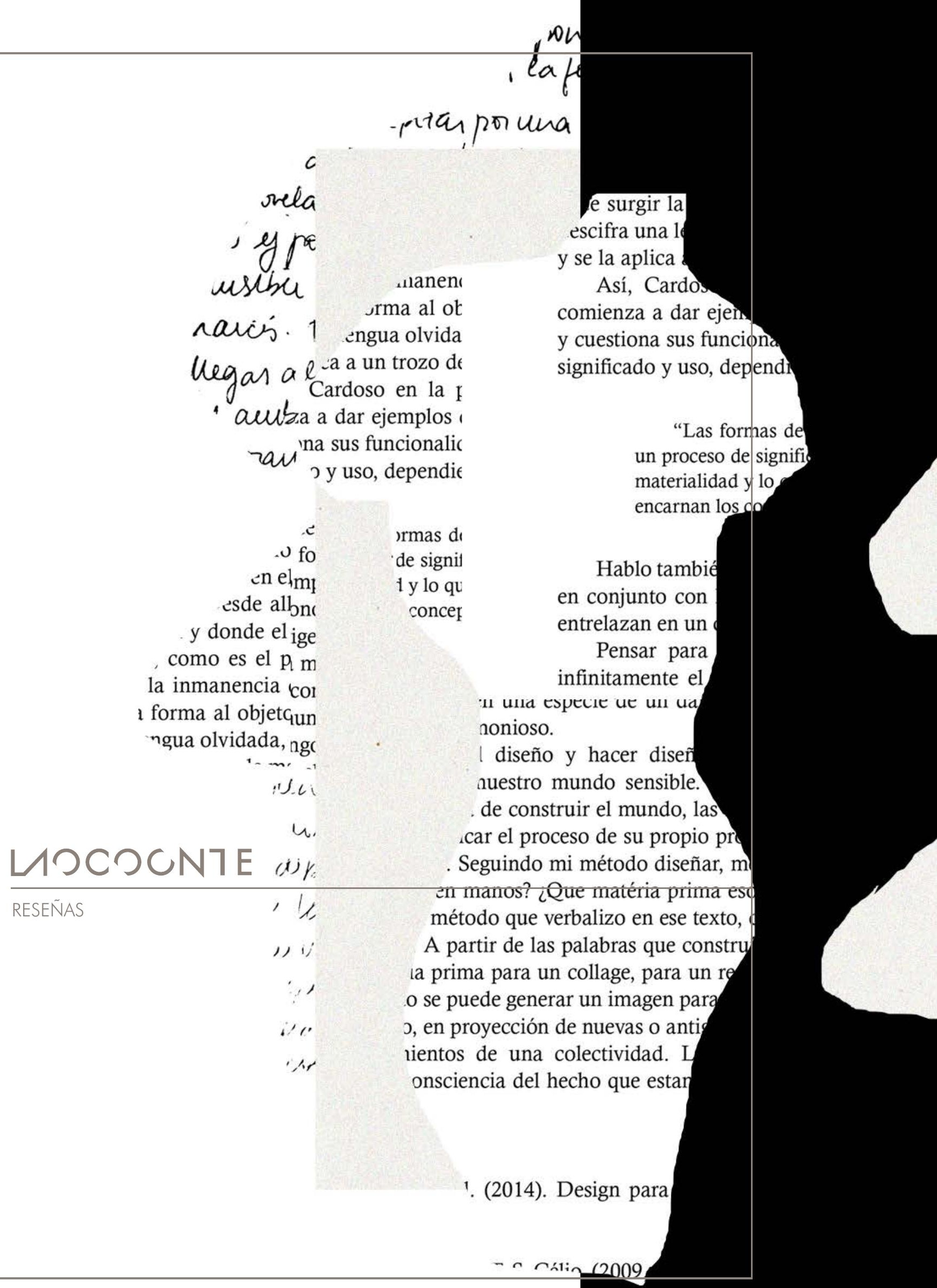




\title{
Walter Gropius. La vida del fundador de la Bauhaus
}

\author{
Jorge Martínez Alcaide
}

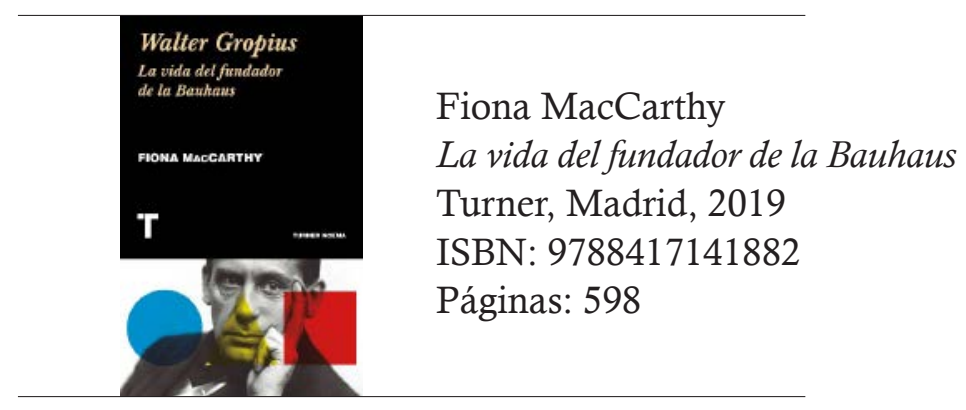

En el año del centenario de la Bauhaus, la prestigiosa y reconocida autora Fiona MacCarthy nos trae esta obra sobre la vida de su creador, Walter Gropius. MacCarthy es experta en el arte y el diseño de los siglos XIX y XX, y ha tenido una prolífica carrera escribiendo en medios tales como The Guardian, The Times Literary Supplement o The New York Review of Books. Su labor como biógrafa ha sido premiada con diversos galardones, destacando el Wolfson History Prize (1994), concedido por su obra William Morris: A Life For Our Time, y el James Tait Black Prize for Biography (2012), concedido por su obra The Last Pre-Raphaelite: Edward Burne-Jones and the Victorian Imagination. Estas credenciales de la autora avalan un estudio pormenorizado, riguroso y exhaustivo del que fuera fundador de la Bauhaus: Walter Gropius (1883-1969).

La obra se divide en tres apartados, al igual que la propia vida de Gropius se desarrolló en tres países diferentes: una primera parte dedicada a Alemania, una segunda a Inglaterra y una tercera a Estados Unidos. Además, se incluye un prefacio y un conjunto de láminas, así como un extenso listado de fuentes y referencias consultadas por la autora. Por todo esto, la presente obra es más que recomendable para todos aquellos amantes de la Bauhaus que quieran profundizar en sus conocimientos sobre ella o sobre su fundador, pero también para aquellos neófitos que quieran adentrarse en el estudio de uno de los principales protagonistas de la arquitectura, el diseño y el arte en el siglo XX.

El estilo de la autora es atrayente, pues va trazando la línea vital de Gropius mientras alterna escenas y episodios de su vida laboral y personal, y de esa manera va describiendo o descubriendo al lector la figura del arquitecto. Y lo interesante de Walter Gropius es que tanto su vida laboral como personal incluían o concernían a personas que o bien ya eran o acabarían siendo verdaderas personalidades del arte y de la escena social a nivel mundial, lo que otorga un plus de misterio a su figura, ya de por sí atrayente.

El libro arranca con la infancia de Gropius en el seno de una familia acomoda-

* Universitat de València, España.jorgemartinezalcaide5@gmail.com 
da de Berlín, pero será a partir de su mayoría de edad cuando comiencen a aparecer los datos interesantes acerca de su persona, pues será cuando por primera vez tome contacto con la arquitectura, realizando una pasantía en un despacho, y será también cuando se matricule en la escuela de arquitectura, pues tenía vocación de arquitecto ya desde su juventud. En esta primera etapa de su vida vivirá sucesos que serán determinantes para su futuro, como por ejemplo el coincidir en uno de los primeros despachos en los que trabajará con un futuro colega como será Mies van der Rohe o enrolarse en el ejército en una Europa pre-bélica, en el $15^{\circ}$ regimiento de húsares.

MacCarthy también destaca los primeros trabajos que acometió Gropius, consistentes en unas viviendas sociales para los trabajadores de la finca rural de un familiar suyo, un encargo que despertará en él esa conciencia de compromiso social que irá siempre ligada a su figura, y reforzará su idea, que nunca abandonaría, de que el ser humano necesita vivir rodeado de zonas verdes.

Pero si hubo un acontecimiento vital para Gropius, fue, según la autora, el hecho de trabajar para Peter Behrens, de quien le asombró su versatilidad, ya que se encargaba no sólo del diseño de sus edificios, sino también de todos sus espacios interiores, así como de los elementos accesorios, tales como cubertería, vajilla o cristalería. Sin duda esto influiría en una de las principales ideas que años después desarrollaría en la Bauhaus, la Gesamtkunstwerk, u "obra de arte total".

Las vicisitudes de la guerra harían de Gropius un héroe de guerra, y propiciaron que éste tuviera una epifanía y se convenciera de que aquello que realmente quería era crear una escuela de arte. A partir de ahí la autora cuenta de manera minuciosa todos los problemas que asediaron al arquitecto hasta que fue designado director de las escuelas de arte y de arquitectura por parte del gobierno de la República de Weimar. La fusión de esas dos escuelas sería el germen de la Bauhaus, para la que Gropius tuvo que buscar profesores que combinaran en sus personas dos aspectos difíciles de aunar: el respeto por la artesanía y la tradición y una nueva y moderna sensibilidad artística.

Será precisamente esta mezcla de seguidores de la tradición de William Morris con esa moderna sensibilidad lo que conforme la identidad de la Bauhaus. El profesorado que contrató Gropius será excepcional, y muchos de sus miembros se convertirán en verdaderas figuras del arte mundial. Algunos de los nombres que, en algún momento, conformarán la plantilla de la Bauhaus serán los siguientes: Gerhard Marcks, Lyonel Feininger, Johannes Itten, Paul Klee, Vassily Kandinsky, Oskar Schlemmer, Gunta Stölzl, Josef Albers, Marcel Breuer, Laszlo Moholy-Nagy o Mies van der Rohe, entre otros.

En cuanto a la Bauhaus, se explica de manera pormenorizada y acertada su proceso de creación, así como su plan de estudios, en el que, a grandes rasgos, Gropius propuso una serie de talleres que tenían al frente a un maestro, y animaba a sus alumnos a que pasaran por varios de ellos para que así pudieran dominar diversas disciplinas: escultura en piedra y madera, cerámica, muebles, oro y otros metales, impresión gráfica, encuadernación y tejido. También se mencionan las paradojas en las que recayó la escuela, como por ejemplo el hecho de que en esta primera etapa de Gropius no incluyó en el plan de estudios la arquitectura. Esto, siendo él mismo arquitecto, le acarreó fuertes críticas, si bien es cierto que él tenía su estudio de arquitectura en la escuela y algunos alumnos trabajaban con él, y que en la segunda fase de la escuela sí que se otorgó mayor importancia a esta disciplina.

Y mientras realizaba estos logros, en el terreno personal su vida también era frené- 
tica, pues tenía una relación amorosa con la que años después sería su primera mujer y madre de su hija Manon, Alma Mahler. Y es que, según los documentos aportados por la autora, Gropius resultaba muy atractivo para las mujeres, lo que le llevó a tener varias amantes y dos esposas. Con la mayoría de sus amantes mantuvo relación epistolar durante su vida, y gracias a ello puede verse cómo Gropius quedó en buenas relaciones con la mayoría de ellas, salvo una excepción: Alma Mahler. Con la viuda del célebre compositor mantendrá una tensa relación durante toda su vida, dominada por fuertes discusiones causadas por la tutela de la hija que tenían en común. Todas estas relaciones aparecen retratadas pormenorizadamente en la presente obra, descubriendo una faceta del arquitecto que el público desconocía.

La autora también menciona el hecho de que en la Bauhaus comenzaron a producirse objetos antes nunca vistos, como por ejemplo la lámpara de mesa MT 8 (algunos de los cuales se pueden observar en las láminas que incluye el libro), y que su director, ayudado por su segunda mujer, Ise, exploraría las opciones de convertir la Bauhaus en una marca comercial y explotar así las posibilidades económicas que ofrecía la escuela, algo que se acabó logrando a medias. Y como no podía ser de otra manera en una biografía de Gropius, la autora escribe acerca de las convicciones sociales y arquitectónicas más profundas del arquitecto, aquellas que le llevaron a crear la Bauhaus y a defenderla durante toda su vida. Pero esto no lo hace en un capítulo dedicado únicamente a su filosofía, algo que el lector agradecería, sino que lo hace a lo largo de toda la obra en breves notas, lo que puede confundir al lector.

Así, el objetivo que tenía Gropius cuando creó la Bauhaus era, siguiendo la estela de sus predecesores William Morris con su movimiento Arts and Crafts y la Deutscher Werkbund, de Muthesius, crear una comunidad de librepensadores en la que reinara la armonía y en la que el arte formara parte de ella; que fuera autosuficiente y que, por encima de todo, estuviese centrada en la búsqueda de la belleza. Como puede verse, es una utopía visionaria como las de Morris y Muthesius, pero con una característica diferente, y es que la Bauhaus, en vez de mirar hacia el pasado, tenía la vista puesta en su futuro, como se vería en las numerosas actividades que llevaría a cabo, desde la fabricación de artículos novedosos hasta la edición de libros (destacando los Bauhausbücher o los libros de la Bauhaus), pasando por acciones verdaderamente revolucionarias como la creación de una nueva tipografía universal desarrollada por Bayer y que prescindía de la mayúscula, en pro de la racionalidad y la eficiencia modernas.

Pero todos estos logros que ayudaron a conformar el panorama del arte y del diseño modernos a escala nacional e internacional, se vieron en parte ensombrecidos cuando Gropius, debido a los ataques políticos hacia su persona, dimitió de su puesto de director de la escuela en favor del profesor Hannes Meyer, de tendencia socialista en una Europa de entreguerras, lo que supondría para la escuela un cambio de rumbo. No obstante, eso no impediría que los nazis pusieran la escuela en su punto de mira y acabaran cerrándola (mientas estaba al frente Mies Van der Rohe), acusándola de producir arte anti alemán, esto es, que fuera funcional y purista, en clara oposición al arte tradicional y rústico, que era el que estaba en consonancia con las ideas de nación de los nazis.

Tras su destitución y el cierre de su querida escuela, Gropius, que veía con tristeza el desmoronamiento de su Alemania natal, lograría un visado de residencia en Inglaterra, pero sin renunciar a su nacionalidad alemana, algo que le habría causado un gran pesar. En Inglaterra el matrimonio Gropius llevará vida de refugiados políticos, 
y si salió adelante fue por el buen hacer del matrimonio formado por Jack y Molly Pritchard, verdaderos mecenas que habían promovido la construcción de Lawn Road Flats, un moderno bloque de apartamentos en Hampstead que destaca por ser el primer edificio doméstico de Reino Unido en el que se usó hormigón armado. Además, eran viviendas de un claro carácter social, dominadas por un ambiente progresista que atrajo a muchos artistas de la época, creándose un clima que a Gropius le recordaba al de la Bauhaus.

A pesar del clima artístico en el que tan a gusto se sentía, faltaban encargos, por eso celebró los pocos que recibió en este país, como la remodelación de sendos recintos del zoo de Londres, o algunas obras para la empresa de desarrollo arquitectónico de su mecenas, Isokon. En cualquier caso, Gropius tendrá que abandonar su interés por las viviendas sociales y dedicarse a realizar encargos burgueses con el mero fin de sobrevivir. Esta situación de precariedad será la que haga que el matrimonio Gropius se mude a EEUU, donde él se pondrá al frente del departamento de arquitectura de Harvard.

Confirmando el tópico, la autora explica cómo EEUU sería para Gropius la tierra de las oportunidades, pues allí pudo llevar a cabo una gran cantidad de proyectos que, de haber seguido en Europa, nunca habrían visto la luz. En esta época la Bauhaus ya estaba consagrándose como un hito del diseño mundial, algo a lo que contribuyó la exposición que se le dedicó en el MoMA. Gropius será el adalid de la modernidad en suelo americano, y con él entrarán con fuerza en el continente los nuevos materiales y las nuevas fórmulas arquitectónicas, a pesar de que había figuras patrias como Frank Lloyd Wright que ya estaban experimentando con ellos y que no veían con buenos ojos la llegada de un competidor de la talla de Gropius. Entre otros proyectos, ahora Gropius se dedicará por fin a la experimentación con casas prefabricadas y al diseño de viviendas en altura, destacando su rascacielos: el Pan Am (1958). Por otra parte, instaurará en este país el trabajo colaborativo que tanto defendía, creando un estudio (el TAC) que recibirá encargos de todo el mundo. Por último, en la última etapa de su vida, recibirá toda una serie de galardones que reconocerán su labor en el campo de la arquitectura y del diseño, y se dedicará a viajar y a organizar el archivo de la Bauhaus.

En definitiva, estamos ante un libro especial, muy recomendable para el lector curioso en general y sobre todo para los interesados en conocer y entender mejor la Bauhaus, pues se ahonda en la figura de su fundador hasta un nivel al que no se había llegado hasta la fecha, aportando datos minuciosos acerca de su turbulenta vida personal y académica que contribuyen a entender mejor el nacimiento de esta escuela. Con esa mezcla de lo personal y lo académico la autora consigue que la lectura sea más ágil, y aunque en ocasiones la balanza se inclina excesivamente hacia lo personal, mantiene siempre una perspectiva que nos ayuda a integrar ambas facetas de su vida. Por otra parte, dado que los capítulos están estructurados por lugares geográficos y etapas, se agradecería algún sub-apartado dentro de los capítulos que ayudara a estructurar mejor los contenidos, puesto que el lector puede abrumarse ante la ingente cantidad de información que aporta la autora y llegar a perder el hilo de la narración.

En cualquier caso, estamos ante una obra que nos acerca más a la figura de un autor que contribuyó a cambiar el panorama artístico y arquitectónico a nivel mundial, y a quien se recuerda, por encima de todo, por ser uno de los grandes filósofos de la arquitectura del siglo XX y por llevar a la práctica una utopía, encarnada en forma de escuela, que cambiaría la forma de producir y entender el arte hasta nuestros días. 


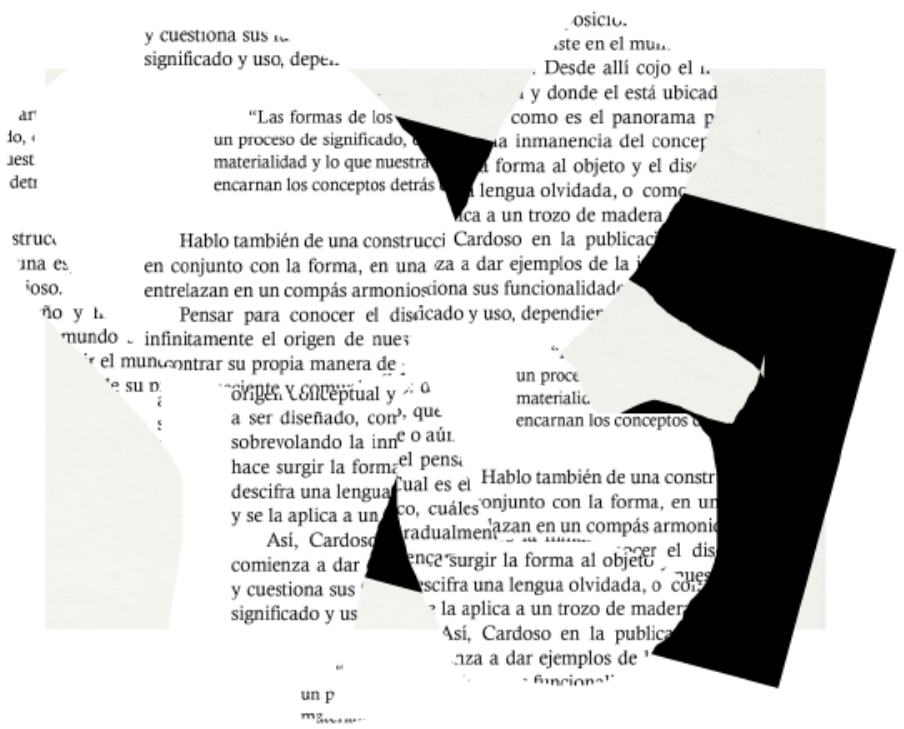

"Lo impreso exige una humildad de espíritu por cuya falta muchas de las bellas artes se tambalean ahora en experimentos de autoconciencia y sensiblería. No hay nada simple ni aburrido en lograr una página transparente. La ostentación vulgar es el doble de fácil que la disciplina".

Beatrice Warde, The Crystal Goblet, or why printings should be invisible (1930)

"El diseño que es objetivo, comprometido con el bien común, bien compuesto y delicado, constituye la base del comportamiento democrático".

Josef Müller-Brockmann, Grid and Design Philosophy (1981) 

EDITA

\section{SEyTA.}

SOCIEDAD ESPAÑLAA
DE ESTETICA Y TEORIA DE LAS ARTES

CON LA COLABORACIÓN DE

\begin{tabular}{|c|c|c|}
\hline 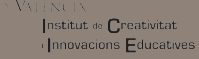 & $\begin{array}{l}\text { VNIVIRSIIA } \\
\text { In VVIIINCI Departament de Filosofia }\end{array}$ & 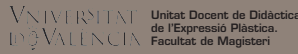 \\
\hline $\begin{array}{l}\text { TitTicA } \\
\text { SoFFA }\end{array}$ & 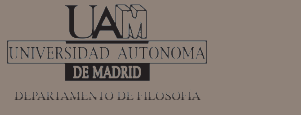 & $\begin{array}{l}\text { UAB } \\
\text { Universitat Autònoma } \\
\text { de Barcelona }\end{array}$ \\
\hline
\end{tabular}

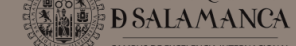

https://ojs.uv.es/index.php/LAOCOONTE/index 